\title{
THE BENEFICIAL EFFECT OF INFORMATION SHARING IN THE INTEGRATED PRODUCTION-DISTRIBUTION PLANNING OF TEXTILE AND APPAREL SUPPLY CHAIN
}

\author{
Imen SAFrA $^{1,2,3, *}$, Aida Jebali ${ }^{4}$, Zied Jemai ${ }^{1,5}$, HANen Bouchriha $^{2}$ AND \\ Asma GhaFFARI ${ }^{1}$
}

\begin{abstract}
The present paper proposes an integrated production-distribution planning approach for a textile and apparel supply chain. Tactical and operational decisions are considered in the proposed multi-product and multi-period planning problem. Using a rolling horizon, the approach aims at defining optimal quantities to produce, to store and to deliver. The integration consists in coordinating informational flows between producer and retailer. Information sharing will allow the producer to estimate more accurately the future replenishment orders that may happen at the operational level and adjust production capacity requirements accordingly. For this purpose, a two-stage planning approach is devised; the first stage deals with the tactical level while the second stage deals with the operational level. The monthly decisions taken at the tactical planning level are accounted for in the operational planning considering a variable rolling horizon. Moreover, accurate forecasts of future replenishment orders are established based on information sharing and introduced in the operational planning to determine the weekly decisions. Linear programming models are used to build production and distribution plans at the tactical and operational levels. Using real-life data from a textile and apparel Tunisian firm, we show that producer-retailer coordination based on the sharing of current sales information, yields significant cost savings reaching up to $20 \%$ of the supply chain cost. These findings can only motivate the partnership between producer and retailer through reliable information sharing in joint tactical-operational and production-distribution planning.
\end{abstract}

Mathematics Subject Classification. 90C05.

Received May 6, 2020. Accepted March 10, 2021.

Keywords. Demand forecasting, textile and apparel supply chain, tactical-operational planning, information sharing, rolling horizon.

1 CentraleSupélec, University of Paris Saclay, 91190 Gif-sur-Yvette, France.

2 LACS, National Engineering School of Tunis, University of Tunis El Manar, 1002 Tunis, Tunisia.

3 National Engineering School of Bizerte, University of Carthage, 7035 Bizerte, Tunisia.

4 SKEMA Business School, Université Côte d'Azur, Paris, France.

5 OASIS, National Engineering School of Tunis, University of Tunis El Manar 1002, Tunis, Tunisia.

${ }^{*}$ Corresponding author: imen.safra@centraliens.net 


\section{INTRODUCTION}

In recent years, the problem of production and distribution planning was of great interest to researchers. Indeed, to face market competitiveness, ensure shorter lead times and achieve cost savings, supply chain actors must manage adequately their resources and plan optimally their activities to meet customers' needs. The main objective is to provide the required product on time and with a competitive cost. For this purpose, a close coordination across the supply chain actors is necessary. This coordination becomes crucial to business success in sectors, where products have a short lifecycle, a volatile demand and face fierce competition. The textile and apparel supply chain is no exception [1].

The major concern of the textile and apparel supply chain is stemming from the uncertainty in the demand. This uncertainty is particularly high in the case of the apparel fashion industry due to customer preferences and tastes that are difficult to predict before the start of the selling season. Achieving a match between demand and supply to minimize unsold quantities and markdowns at the end of the selling season while, at the same time, ensuring the availability of demanded products is very challenging in this case. In order to better adjust the supply to the demand, many textile apparel companies opt for producing a certain quantity of each product before the start of its selling season and the rest during its selling season. A pre-season order is hence placed by the retailer based on demand forecast. After observing the sales over the first weeks of the selling season, other replenishment orders can be placed by the retailer based on more accurate forecasts of the demand. Some companies, such as Zara, can even decide to stop the production and the display of certain items over a selling season to replace them by others that match better customer preferences [10]. This requires production flexibility, reduced replenishment lead times and coordination of the textile and apparel supply chain while maintaining its cost-effectiveness.

In this work, we address a multi-period production-distribution planning problem arising in global textile and apparel supply chain, involving multiple actors dispersed all around the world, and offering a wide variety of products with short lifespans and high demand variability. Both pre-season orders with medium lead time and in-season replenishment orders with short lead time are accounted for in production and distribution planning. Because of the difference between the lead time of pre-season and replenishment orders, the considered problem integrates production and distribution decisions pertaining to the tactical and operational planning levels. In addition, this multi-level planning problem is investigated while considering that the retailer shares information on the in-season sales with the producer. Therefore, the impact of this information sharing on the overall cost of the textile and apparel supply chain is assessed.

The literature on integrated production-distribution planning problem is abundant as shown by Mula et al. [28], Chen [7], Fahimnia et al. [12] and Moons et al. [25]. Different variants of this problem have been investigated: some works involve a single manufacturer and/or a single retailer $[3,8,30]$ with multiple products, while others take into account a single product $[6,24,35,36]$. Some other papers study the case of multiple manufacturers with multiple products $[18,19,43]$, though the latter are limited to a single period. Other works consider the multi-product and multi-period problem [15, 23, 31,34,37].

Noticeably, many integrated production-distribution planning models are sector specific and have been especially devoted to time-sensitive [36] and/or perishable products such as medicine [15], food [8,13,22], dairy products [16], newspapers [33] and fashion apparel [2,11,14,34].

Nevertheless, the works that incorporated tactical and operational planning decisions are rather scarce [17, $32,34,39]$. On the other hand, only a few studies consider information sharing and demand forecasting $[21,45,46]$ and do not highlight the value and benefits of information sharing.

To the best of our knowledge, integrated production-distribution planning that incorporates tactical and operational decisions with demand forecasting based on information sharing in the textile and apparel supply chain has not been investigated. This paper is devoted to fill this gap.

In this paper, we propose a novel approach for the integrated tactical-operational production-distribution planning of textile and apparel supply chain. We ensure production flexibility may match the supply and the demand via subcontracting and overtime. In addition, we incorporate in-season demand forecasting based on 
information shared between producer and retailer. Information sharing increases the reliability of the forecasting system. We use logistic diffusion model to forecast in-season replenishment orders based on observed sales. We use more accurate forecast of in-season replenishment orders as inputs in the operational planning model. We apply the proposed approach to a real case study involving a Tunisian textile and apparel company. We assess the value and the benefits of information sharing and its impact on the cost-effectiveness of the considered textile and apparel supply chain.

The remainder of the paper is organized as follows. Section 2 presents a literature review of related works and emphasizes the contribution of this paper. Section 3 describes the proposed approach for tactical-operational production-distribution planning with information sharing. Section 4 reports the mathematical model formulation. Section 5 describes the method used to forecast future replenishment orders. Section 6 details computational results and quantifies the value of sharing information by comparing the corresponding results to their counterparts obtained with no information sharing.

\section{Literature REVIEW}

The literature review is structured into 4 subsections. In the first subsection, we focus on the works that investigated the integrated production-distribution planning while incorporating tactical and operational decisions. The second subsection presents the papers that tackled textile and apparel supply chain planning problems. The third subsection presents the notable works on demand forecasting in textile and apparel industry. The main contribution of this research is summarized in subsection 4 .

\subsection{Integrated production-distribution planning}

As shown by the existing literature surveys [7, 12, 25, 28], the integrated production-distribution planning problem has been widely explored in recent years. We focus here on the works that are most relevant to our study.

Armentano et al. [3] investigated a capacity-constrained plant producing and distributing a number of items using a fleet of homogenous vehicles. They approximately solved the production-distribution planning problem using tabu search. Chen and Vairaktarakis [8] studied an integrated scheduling model of production and distribution operations that occur in the computer and food catering service industries. Pundoor and Chen [30] studied an integrated production-distribution scheduling model in a two-stage supply chain. The problem is to find jointly a cyclic production schedule and a cyclic delivery schedule so that the customer demand for each product is satisfied without backlog at the least total cost. Two production and delivery scheduling policies were considered based on whether the production cycle time is equal to the delivery cycle time or is an integer multiple of the delivery cycle time. The general problems stemming from these two policies were heuristically solved.

Considering single product, Boudia and Prins [6] used a memetic algorithm to solve an integrated productiondistribution problem where splitting demand and shortage are not allowed. Liao et al. [24] proposed a multiobjective dual channel supply chain model. Their heuristic approach integrates genetic algorithms, a clustering analysis, a non-dominated sorting genetic algorithm-II, and a technique for order preference by similarity to ideal solution. More recently, Sarkar and Giri [35] formulated an integrated supply chain model with backorder price discount by assuming the replenishment lead time as a linear function of order size, setup time and transportation time. Sarkar et al. [36] investigate how replenishment lead time affects the backorder quantity and possible way to increase the backorder rate during shortage.

Tsiakis et al. [43] devised a mixed integer linear programming model (MILP) to determine the optimal configuration of a production and distribution network subject to operational and financial constraints. The proposed single-period model accounts for multiple manufacturers, multiple products and considers outsourcing of production whenever internal capacity cannot satisfy the demand. A case study for the coatings business unit of a global specialty chemicals manufacturer was used to show the interest of the proposed model. Kim et al. [19] formulated an integrated model of supply network and production planning among refineries. A Simulation 
and optimization approach was proposed to solve the problem. Keskin and Üster [18] presented a mixed-integer problem formulation that facilitates the development of efficient heuristic procedures. They provided metaheuristic procedures, including a population-based scatter search with path relinking and trajectory-based local and tabu search, for the solution of the problem.

Other works considered the multi-product and multi-period problem. Liu and Papageorgiou [23] developed a multi-objective mixed-integer linear programming approach with the objective of minimizing total cost, total flow time and total lost sales. They also considered two strategies to expand plants' capacities. Ghasemi Bijaghini and SeyedHosseini [15] formulated a bi-level planning model in the medicine supply chain. The first objective function targets the minimization of the budget while the second one aims at the minimization of the shortage associated with lost sales. A robust approach was used to account for the uncertainty of some parameters using Benders decomposition algorithm. Selim et al. [37] developed a multiobjective MILP model for collaborative production-distribution planning problem using fuzzy goal programming approach. Ratna Kumar et al. [31] proposed an integrated production-distribution planning problem that considers fixed cost, setup cost, and core demand for multiple products in an environment with backordering and order refusals. They carried a sensitivity analysis to investigate the behavior of the model when input conditions are varied.

Markedly, only a few works dealt with the integration of the tactical and operational planning decisions pertaining to production and distribution [34]. Kanyalkar and Adil [17] addressed an integrated multi-product, parallel multi-plant production and distribution problem where the supplying plant is dynamically determined for each sales point. Rømo et al. [32] devised a single period mixed-integer program to optimize the network configuration and routing for the main Norwegian shipper of natural gas. Sousa et al. [39] presented a two-level planning approach for the redesign and optimisation of production and distribution of a global agrochemicals supply chain.

At this level, it is worth noting that the above-mentioned works, and especially those that consider multiproduct production and distribution planning, can be adjusted to wider real world applications [12].

\subsection{Textile and apparel supply chain planning models}

In the following, we focus on the works that are specific to textile and apparel sector. Felfel et al. [14] developed a multi-stage stochastic program for a tactical multi-product, multi-period, multi-site supply chain production and transportation planning problem under customer demand uncertainty. Darvishi et al. [11] also investigated the tactical aggregate planning level. They formulated the problem using a mixed integer nonlinear mathematical program. They developed an approach based on hybrid fuzzy-robust stochastic method in production planning with cross-docking. Ait-Alla et al. [2] proposed a stochastic model for robust production and transportation planning in the fashion apparel industry using conditional value at risk. They incorporated demand scenarios and their respective probabilities in a model whose objective is to maximize the expected profit.

All the papers mentioned so far do not integrate tactical and operational decision levels in textile and apparel supply chain planning. However, this integration is primordial to ensure decision process consistency and achieve production-distribution planning objectives. For this purpose, Safra et al. [34] proposed a twostage approach for production-distribution planning in the textile and apparel supply chain that considers coordination between tactical and operational decision levels. The considered production-distribution planning problem takes into account different finished items that could be produced either using internal production capacity or subcontractors' manufacturing units. The finished items are then delivered to customers, from warehouses, using different transportation modes. Overtime and subcontracting are used as a flexibility potential to overcome internal production capacity constraints in order to satisfy customer demands and respect lead times. In addition, a reserve production capacity is considered at the tactical planning level, and it is shown that this reduces notably the supply chain cost. The planning problem is studied for the case of no information sharing between the manufacturer and the retailer. However, as revealed in the recent review dedicated to fashion retail supply chain (FRSC) management [44], information sharing can contribute to improving the quality of FRSC decisions. 
In recent years, research streams on information sharing are emerging given that many works advocated that the latter can be a key factor for a firm's success. Li et al. [21] developed a system dynamics model to evaluate the impact of the disruption at the end-customers, and how it can be mitigated through information sharing among different supply chain echelons. Wu et al. [45] evaluated the benefits of sharing information on suppliers product quality with the buyer. Yang and Fan [46] used control theory modeling and simulation showing that information sharing reduces the bullwhip effect under demand disruptions. Notably, none of these works considers information sharing in the integrated production and distribution planning with consideration of tactical and operational decisions.

Information sharing is aimed at improving the quality of demand forecasts and hence the effectiveness of the resulting planning decisions. This is particularly prominent in the textile and apparel supply chain where demand forecasting is highly challenging [44]. Thus, many researches have been devoted to developing demand forecasting models for the textile and apparel products. The following subsection presents some of these works.

\subsection{Demand forecasting in textile and apparel industry}

Recall that textile and apparel products are single-period products with short lifespan that are characterised by high demand uncertainty. As noted in Nenni et al. [29], the lack of historical demand data in this case constitutes one of the foremost barriers of forecasting. To overcome this issue, Wen et al. [44] advocated the recourse to updated market information, that is close to the coming season, to forecast pre-season orders. Şen and Zhang [38] rather promoted the use of the early sales data at the beginning of the season to update the forecast for later in-season demand.

As far as demand forecasting is concerned, it is classically conducted while using statistical methods such as exponential smoothing and ARIMA. However, as stated by Berbain et al. [5], these forecasting methods require a significant amount of demand history that is unavailable for textile and apparel items. Therefore, some methods have been adjusted to account for the characteristics of textile and apparel products. Thomassey et al. [41,42] developed a forecasting system based on soft computing techniques such as fuzzy logic, neural networks and evolutionary procedures. Mostard et al. [27] propose new forecasting methods based on advance demand information and perform a case study to compare them to existing ones based on advance demand information and also to methods based on expert judgments. Other works [4,47,48] used Artificial Neural Network (ANN) to forecast the demand of fashion products. Although the ANN algorithm provided accurate demand forecasts, it is impractical because of the high training time required to obtain the forecast.

To face the lack of sales historical data, diffusion models, such as Logistic and Gompertz models, can also be considered to forecast the demand of new products with no or some sales history [26]. For standard life cycle curve products, these models try to determine future sales by quantifying the long-term saturation level, the period of sales peak over product life cycle and the intensity of the introduction phase [20]. Otherwise, for products whose sales does not follow the standard shape of life cycle curve (one or more phases are absent), Ching-Chin et al. [9] proposed a model based on the average sales of similar product families.

In all cases, the forecast model to consider must take into account any information deemed appropriate to the logistic context and to the application field. That is why, in this work, we propose to use the Logistic diffusion model to predict replenishment orders that may arrive to the manufacturer over the current selling season. First, it is fit to textile and apparel products as it can be used even if there is no or limited historical data on the demand. Moreover, this choice can be justified by the adequacy of textile and apparel products to the standard life cycle curve where sales volumes follow the four phases of introduction, growth, maturity and decline. More importantly, the Logistic model is easy to implement while repeatedly adjusting its parameters based on in-season sales information shared between the retailer and the producer. Henceforth, based on this forecasting scheme, the benefits and value of information sharing in integrated production and distribution planning in the the textile and apparel supply chain will be assessed. 


\subsection{Contribution}

The main contribution of this work relies in the consideration of information sharing as a lever to achieve a better match between supply and demand in the textile and apparel supply chain while meeting customer needs on time and at the least cost. The integrated tactical-operational production-distribution planning approach proposed in Safra et al. [34] is therefore extended in order to incorporate replenishment order forecast while accounting for observed in-season sales that the retailer accepts to share with the manufacturer. With this information sharing, the manufacturer will be able to establish more accurate forecasts of future replenishment orders. We evaluate the total supply chain cost while comparing the supply chain performance for the cases with and without information sharing. The benefits and value of information sharing is evidenced through this comparison. The proposed approach is applied to a real life textile and apparel company.

\section{Production-Distribution PlanNing APPROACH With INFORMATion SHARING}

\subsection{Problem description}

The considered textile and apparel supply chain model is based on a real life case study which is representative of the vast majority of current worldwide textile, apparel and fashion supply chains. The case study considers the supply chain of a textile and apparel manufacturing company that belongs to one of the largest industrial groups in Tunisia. The group has its own women apparel and fashion brand and operates a large number of retail stores. As illustrated in Figure 1, the supply chain network comprises:

- A set of manufacturing units denoted by $K=U \cup V$, where $U$ is the set of internal manufacturing units located in Tunisia and $V$ is the set of subcontractors' manufacturing units located either in Tunisia, or overseas (in China).

- A set of warehouses located in Tunisia, denoted by $J$.

- A set of retailers, denoted by $I$, where the majority of them are located in the European market, and a few in the Tunisian market.

In comparison to local subcontracting, overseas subcontracting induces higher transportation costs because of their distant locations and longer lead times. But they offer very competitive prices, especially for basic products. Local subcontractors are however more flexible, as they are close at hand. It is worth noting at this level that our model, detailed thereafter in Section 4, optimally determines the subcontactors to be hired over each time period $t, t \in[1 \ldots T]$ where $T$ is the number of periods included in the planning horizon.

The considered textile and apparel company is adopting a commit-to-delivery business mode. When receiving retailer orders, it validates a delivery due date and is responsible for the shipping cost. Finished products are

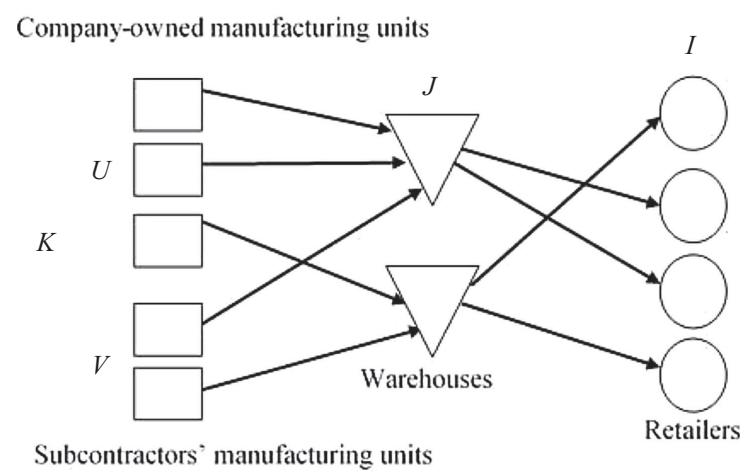

Figure 1. Supply Chain network. 
shipped immediately towards the warehouses where they are gathered and stored till their delivery time. More than four million pieces per year are sold to the most well-known clothing brands and retailers (Lacoste, Kookaï, Promod, Camaïeu, Jaqueline Riu, Cache Cache, Bonprix, Morgan, Go Sport, Orsay, Dixit ...). A set of transportation modes, noted by $L$, may be used for delivery operations, namely trucks, ships or aircraft. Manufacturers receive two kinds of orders: pre-season orders and replenishment orders. Pre-season orders are due within months because the ordered products have to be sold during the next season. Replenishment orders have shorter lead times than pre-season orders. They prevent stockouts of products sold over the current selling season.

Each retailer $i$ expresses a firm demand for product $p$ to be delivered at period $t\left(\mathrm{DF}_{\text {pit }}\right)$. Forecasted demand for product $p$ to meet future needs of retailer $i$ in period $t$ is denoted by $\mathrm{DP}_{p i t}$. Orders are assigned to manufacturing units $k$ characterized by a production capacity $\left(P_{k t}\right)$ over time period $t$. The production of each item $p$ in site $k$ over period $t$ incurs either a variable and a fixed cost $\left(\mathrm{CV}_{p k t}, \mathrm{CF}_{p k t}\right)$ or a subcontracting cost $\left(\mathrm{CS}_{p k t}\right)$. For more production flexibility, an overtime production capacity in internal manufacturing unit $k$ at period $t$ $\left(\mathrm{PO}_{k t}\right)$ is considered. Consequently, an overtime production cost of product $p$ in internal manufacturing unit $k$ at period $t\left(\mathrm{CO}_{p k t}\right)$ is taken into account. Underutilization cost of internal production capacity at the manufacturing unit $k$ over period $t\left(\mathrm{CU}_{k t}\right)$ is also considered to penalize the unused available resources. Each product $p$ is characterized by a production lead time $\left(T_{p}\right)$ and a unit volume $\left(V_{p}\right)$. Inventory holding cost of product $p$ over period $t$ at warehouse $j$ is $\left(\mathrm{CI}_{p j t}\right)$. Each warehouse $j$ has a limited storage capacity $\left(W_{j}\right)$. Transportation mode $l$ is characterized by a limited capacity $\left(C_{l}\right)$ and a transportation lead time $\left(d_{l}\right)$. For each each product $p$, a variable and a fixed distribution cost from manufacturing unit $k$ to warehouse $j\left(\mathrm{CV} 1_{k j p l}, \mathrm{CF} 1_{k j l}\right)$, and from warehouse $j$ to retailer $i\left(\mathrm{CV} 2_{j i p l}, \mathrm{CF} 2_{j i l}\right)$, over period $t$, are also considered.

\subsection{The rolling horizon planning approach}

The considered production-distribution planning problem integrates tactical and operational decisions. The objective is to ensure the consistency of these two planning decisions while incorporating both pre-season and replenishment orders. It is important to note here that the lead time of pre-season orders are of several months (6 months at most) while the lead time of replenishment orders are of several weeks (8 weeks at most). As portrayed in Figure 2, the proposed sequential multi-level planning approach uses two models: (1) a tactical model and (2) an operational model. This decomposition is justified by problem complexity $[12,34]$.

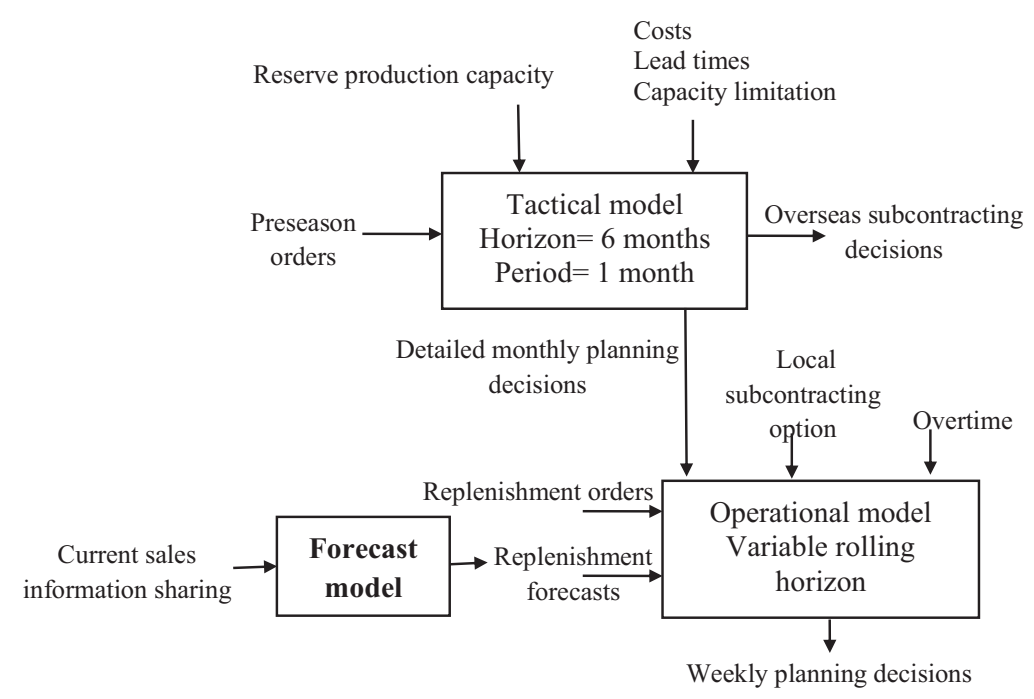

FiguRE 2. Planning approach. 
The tactical model (Fig. 2) includes six 4-week periods planning horizon in order to contain the lead time of pre-season orders. For the sake of simplication, hereafter, each 4 -week period is referred to as a month. The tactical model determines monthly quantities to produce, store and deliver to retailers. Overseas subcontractors' assignments determined at the tactical level are firm. To face unforeseen and urgent demand that may happen over weeks, a reserve production capacity is considered at the tactical level. The latter provides a lever for incorporating replenishment orders at operational level. The objective is to lower supply chain costs and increase customer satisfaction by delivering the quantities of products they ordered in full and on time. A monthly rolling horizon is considered to integrate newly received preseason orders.

At the operational level, a variable planning horizon including eight to eleven 1-week periods is considered (Fig. 3). The operational model incorporates the output of the tactical model, the received replenishment orders and replenishment order forecasts based on shared information on current sales as inputs to determine the quantities to produce, store and deliver to retailers over each week of the planning horizon. A weekly rolling horizon is considered to integrate newly received replenishment orders. At this level, we recall that 8 weeks is the maximum lead time for a replenishment order. As shown in Figure 3, the length of the operational planning horizon is adjusted in order to guarantee the integration of all received replenishment orders. In this operational model overseas subcontractors are not considered.

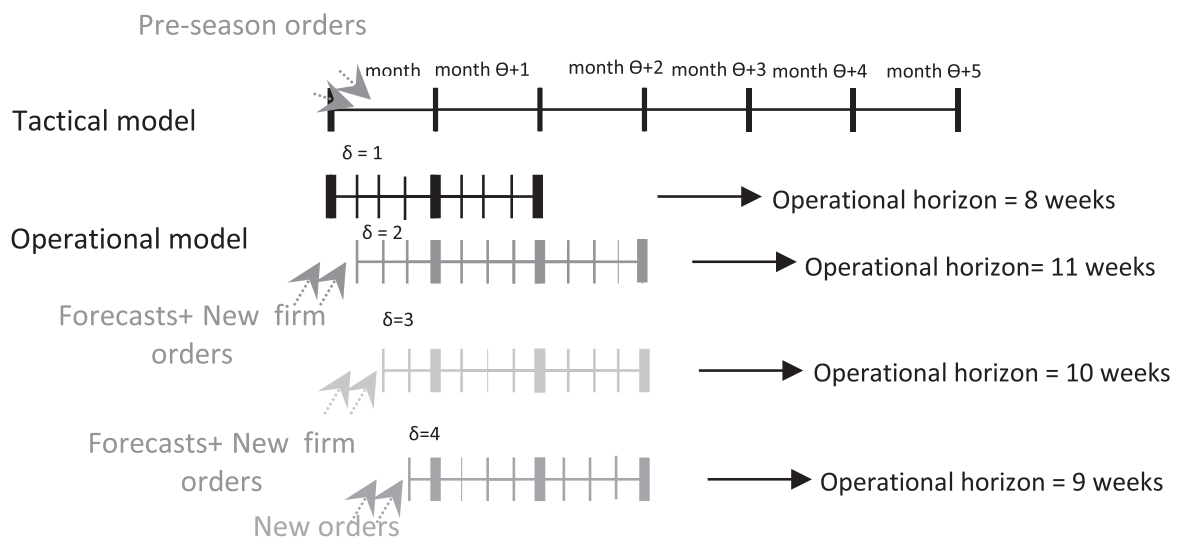

FIGURE 3. Planning horizons description.

Pre-season orders are for products belonging to the new collection of the next selling season. Commitments are thus pronounced on these orders and the tied production assignment have to be respected at the operational level. When a new pre-season order, with a delivery lead time exceeding the length of the operational planning horizon, arrives; it is introduced to the tactical planning model of the following month to decide on production assignment, taking into account overseas subcontractors. Moreover, at the operational level, it is not excluded to opt for local subcontracting or to produce during overtime in order to meet unforeseen demand (Fig. 2).

In this work, the proposed planning approach considers information sharing on current sales between the retailer and the producer. Hence, it levels up the approach presented in Safra et al. [34] to shed the light on the interest of information sharing and its impact on the total supply chain cost.

\section{Mathematical Formulation}

The proposed tactical-operational production-distribution planning approach deals with two linear programming models. The tactical planning model is similar the one proposed in Safra et al. [34] and will be presented in Appendix A for the sake of completeness. 
Otherwise, to support the aim of this paper, the operational model which considers replenishment order forecasts based on shared sales data between the retailer and the producer, deals with planning replenishment order forecasts.

In addition to the notation introducted in Section 3.1 (with consideration of a 1-week period), the operational model considers the tactical planned quantities of product $p$ to be produced at manufacturing unit $k$ over the first month, the second month and the third month, denoted hereafter by $X 1_{p k}, X 2_{p k}$ and $X 3_{p k}$, respectively. Obviously, these inputs of the operational model are derived from the solution of the tactical planning model. Furthermore, in the operational model, we consider the following decision variables:

\section{Integer decision variables}

$\mathrm{XP}_{p k t}$ : quantity of product $p \in P$ to produce at manufacturing unit $k \in K$ over period $t \in T$ tied to forecasted replenishment orders.

$\mathrm{XF}_{p k t}$ : quantity of product $p \in P$ to produce at manufacturing unit $k \in K$ over period $t \in T$ tied to received pre-season and replenishment orders

$\mathrm{XP}_{p k t}^{\prime}$ : quantity of product $p \in P$ to produce during overtime at manufacturing unit $k \in U$ over period $t \in T$ tied to forecasted replenishment order.

$\mathrm{XF}_{p k t}^{\prime}$ : quantity of product $p \in P$ to produce during overtime at plant $k \in U$ over period $t \in T$ tied to received pre-season and replenishment orders.

$\mathrm{UP}_{k t}$ : unused production capacity at manufacturing unit $k \in U$ over period $t \in T$.

$\mathrm{JP}_{p j t}$ : inventory level of product $p \in P$ at warehouse $j \in J$ at the end of period $t \in T$ to tied to forecasted replenishment orders.

$\mathrm{JF}_{p j t}$ : inventory level of product $p \in P$ at warehouse $j \in J$ at the end of period $t \in T$ tied to received pre-season and replenishment orders

$\mathrm{ZP} 1_{k j p l t}$ : quantity of product $p$ to be delivered from plant $k \in K$ to warehouse $j \in J$ by transportation mode $l \in L$ over period $t \in T$ tied to forecasted replenishment orders.

$\mathrm{ZF} 1_{\text {kjplt }}$ : quantity of product $p$ delivered from plant $k \in K$ to warehouse $j \in J$ by transportation mode $l \in L$ over period $t \in T \mathrm{t}$ ied to received pre-season and replenishment orders.

$\mathrm{ZP} 2_{j i p l t}$ : quantity of product $p \in P$ to be delivered from warehouse $j \in J$ to retailer $I \in I$ by transportation mode $l \in L$ over period $t \in T$ tied to forecasted replenishment orders.

ZF2 $2_{\text {jiplt }}$ : quantity of product $p \in P$ delivered from warehouse $j \in J$ to retailer $I \in I$ by transportation mode $l \in L$ over period $t \in T$ tied to received pre-season and replenishment orders.

$\mathrm{NP} 1_{k j l t}$ : number of times transportation mode $l \in L$ is used to transport products from plant $k \in K$ to warehouse $j \in J$ over period $t \in T$.

NP2 $2_{\text {jilt }}$ : number of times transportation mode $l \in L$ is used to transport products from warehouse $j \in J$ to retailer $i \in I$ over period $t \in T$.

Binary decision variables

$\mathrm{YP}_{p k t}=1$ if demand for product $p \in P$ tied to forecasted replenishment order is processed at manufacturing unit $k \in K$ over period $t \in T, 0$ otherwise.

$\mathrm{YF}_{p k t}=1$ if demand for product $p \in P$ tied to received pre-season and replenishment orders is processed at plant $k \in K$ over period $t \in T, 0$ otherwise.

$\mathrm{YP}_{p k t}^{\prime}=1$ if demand for product $p \in P$ tied to forecasted replenishment order is processed during overtime at plant $k \in U$ over period $t \in T, 0$ otherwise.

$\mathrm{YF}_{p k t}^{\prime}=1$ if demand for product $p \in P$ tied to received pre-season and replenishment orders is processed during overtime at plant $k \in U$ over period $t \in T, 0$ otherwise. 


\section{Model formulation}

Thee problem is formulated as a MILP which aims to minimize the overall cin the considered logistics network.

$$
\begin{aligned}
\operatorname{Min} & \left(\sum_{t \in T} \sum_{p \in P} \sum_{k \in U} \mathrm{CV}_{p k t} *\left(\mathrm{XP}_{p k t}+\mathrm{XF}_{p k t}\right)+\sum_{t \in T} \sum_{p \in P} \sum_{k \in U} \mathrm{CF}_{p k t} *\left(\mathrm{YP}_{p k t}+\mathrm{YF}_{p k t}\right)\right. \\
& \times \sum_{t \in T} \sum_{p \in P} \sum_{k \in U} \mathrm{CF}_{p k t} *\left(\mathrm{YP}_{p k t}^{\prime}+\mathrm{YF}_{p k t}^{\prime}\right)+\sum_{t \in T} \sum_{p \in P} \sum_{k \in V} \mathrm{CS}_{p k t} *\left(\mathrm{XP}_{p k t}+\mathrm{XF}_{p k t}\right) \\
& \sum_{t \in T} \sum_{p \in P} \sum_{k \in U} \mathrm{CO}_{p k t} *\left(\mathrm{XP}_{p k t}^{\prime}+\mathrm{XF}_{p k t}^{\prime}\right)+\sum_{t \in T} \sum_{k \in U} \mathrm{CU}_{k t} * \mathrm{UP}_{k t} \\
& +\sum_{t \in T} \sum_{p \in P} \sum_{j \in J} \mathrm{CI}_{p j t} *\left(\frac{\mathrm{JP}_{p j t}+\mathrm{JP}_{p j t+1}}{2}+\frac{\mathrm{JF}_{p j t}+\mathrm{JF}_{p j t+1}}{2}\right)+\sum_{l \in L} \sum_{t \in T} \sum_{p \in P} \sum_{k \in K} \sum_{j \in J} \mathrm{CV} 1_{k j p l} \\
& * V_{p} *\left(\mathrm{ZP}_{k j p l t}+\mathrm{ZF}_{k j p l t}\right)+\sum_{p \in P} \sum_{l \in L} \sum_{t \in T} \sum_{k \in K} \sum_{j \in J} \mathrm{CF} 1_{k j l} * \mathrm{NP} 1_{k j l t} \\
& \left.+\sum_{t \in T} \sum_{p \in P} \sum_{i \in I} \sum_{j \in J} \sum_{l \in L} \mathrm{CV}_{j i p l} * V_{p} *\left(\mathrm{ZP} 2_{j i p l t}+\mathrm{ZF} 2_{j i p l t}\right)+\sum_{p \in P} \sum_{t \in T} \sum_{i \in I} \sum_{j \in J} \sum_{l \in L} \mathrm{CF}_{j i l} * \mathrm{NP} 2_{j i l t}\right)
\end{aligned}
$$

Subject to

$$
\begin{aligned}
& \mathrm{JP}_{p j t}=\mathrm{JP}_{p j t-1}+\sum_{l \in L} \sum_{k \in K} \mathrm{ZP} 1_{k j p l t}-\sum_{i \in I} \sum_{l \in L} \mathrm{ZP} 2_{j i p l t} \quad p \in P ; j \in J ; t \in T \\
& \mathrm{JF}_{p j t}=\mathrm{JF}_{p j t-1}+\sum_{l \in L} \sum_{k \in K} \mathrm{ZF} 1_{k j p l t}-\sum_{i \in I} \sum_{l \in L} \mathrm{ZF} 2_{j i p l t} \quad p \in P ; j \in J ; t \in T \\
& \sum_{p \in P}\left(\mathrm{JP}_{p j t}+\mathrm{JF}_{p j t}\right) \leq W_{j} \\
& j \in J ; t \in T \\
& \mathrm{XP}_{p k t} \leq M *\left(\mathrm{YP}_{p k t}+\mathrm{YP}_{p k^{\prime} t}^{\prime}\right) \\
& p \in P ; k \in K ; k^{\prime} \in U ; t \in T \\
& \mathrm{XF}_{p k t} \leq M *\left(\mathrm{YF}_{p k t}+\mathrm{YF}_{p k^{\prime} t}^{\prime}\right) \\
& p \in P ; k \in K ; k^{\prime} \in U ; t \in T \\
& \mathrm{YP}_{p k t} \leq \mathrm{XP}_{p k t} \\
& p \in P ; k \in K ; t \in T \\
& \mathrm{YF}_{p k t} \leq \mathrm{XF}_{p k t} \\
& \mathrm{XP}_{p k^{\prime} t}^{\prime} \leq M *\left(\mathrm{YP}_{p k^{\prime} t}^{\prime}+\mathrm{YP}_{p k t}\right) \\
& p \in P ; k \in K ; t \in T \\
& \mathrm{XF}_{p k^{\prime} t}^{\prime} \leq M *\left(\mathrm{YF}_{p k^{\prime} t}^{\prime}+\mathrm{YF}_{p k t}\right) \\
& p \in P ; k \in K ; k^{\prime} \in U ; t \in T \\
& p \in P ; k \in K ; k^{\prime} \in U ; t \in T \\
& \mathrm{YP}_{p k^{\prime} t}^{\prime} \leq \mathrm{XP}_{p k^{\prime} t}^{\prime} \\
& p \in P ; k^{\prime} \in U ; t \in T \\
& \mathrm{YF}_{p k^{\prime} t}^{\prime} \leq \mathrm{XF}_{p k^{\prime} t}^{\prime} \\
& p \in P ; k^{\prime} \in U ; t \in T \\
& \mathrm{YP}_{p k^{\prime} t}^{\prime}+\mathrm{YP}_{p k t} \leq 1 \\
& p \in P ; k \in K ; k^{\prime} \in U ; t \in T \\
& \mathrm{YF}_{p k^{\prime} t}^{\prime}+\mathrm{YF}_{p k t} \leq 1 \\
& p \in P ; k \in K ; k^{\prime} \in U ; t \in T \\
& \sum_{p \in P} T_{p} *\left(\mathrm{XP}_{p k t}+\mathrm{XF}_{p k t}\right) \leq P_{k t} \\
& k \in K ; t \in T \\
& \sum_{p \in P} T_{p} *\left(\mathrm{XP}_{p k^{\prime} t}^{\prime}+\mathrm{XF}_{p k^{\prime} t}^{\prime}\right) \leq P O_{k^{\prime} t} \\
& k^{\prime} \in U ; t \in T \\
& \mathrm{XP}_{p k 1}=0 \\
& p \in P ; k \in K \\
& \mathrm{XP}_{p k^{\prime} 1}^{\prime}=0 \\
& p \in P ; k^{\prime} \in U \\
& \sum_{t \in S 1}\left(\mathrm{XF}_{p k t}+\mathrm{XF}_{p k^{\prime} t}^{\prime}\right) \geq X 1_{p k}
\end{aligned}
$$




$$
\begin{aligned}
& \sum_{t \in S 2}\left(\mathrm{XF}_{p k t}+\mathrm{XF}_{p k^{\prime} t}^{\prime}\right) \geq X 1_{p k} \\
& p \in P ; k \in K ; k^{\prime} \in U \text {; } \\
& S 2=\{1, \ldots, h-8\} ; 8<h \leq 11 \\
& \sum_{t \in S 3}\left(\mathrm{XF}_{p k t}+\mathrm{XF}_{p k^{\prime} t}^{\prime}\right) \geq X 2_{p k} \\
& p \in P ; k \in K ; k^{\prime} \in U \text {; } \\
& S 3=\{1, \ldots, 8\} \\
& \sum_{t \in S 4}\left(\mathrm{XF}_{p k t}+\mathrm{XF}_{p k^{\prime} t}^{\prime}\right) \geq X 2_{p k} \\
& p \in P ; k \in K ; k^{\prime} \in U \text {; } \\
& S 4=\{h-7, \ldots, h-4\} ; 8<h \leq 11 \\
& \sum_{t \in S 5}\left(\mathrm{XF}_{p k t}+\mathrm{XF}_{p k^{\prime} t}^{\prime}\right) \geq X 3_{p k} \\
& p \in P ; k \in K ; k^{\prime} \in U \text {; } \\
& S 5=\{h-3, \ldots, h\} ; 8<h \leq 11 \\
& \mathrm{UP}_{k^{\prime} t} \geq P_{k^{\prime} t}-\sum_{p \in P} T_{p} *\left(\mathrm{XP}_{p k^{\prime} t}+\mathrm{XF}_{p k^{\prime} t}\right) \\
& k^{\prime} \in U ; t \in T \\
& \mathrm{XP}_{p k^{\prime} t}^{\prime}+\mathrm{XP}_{p k t}=\sum_{l \in L} \sum_{j \in J} \mathrm{ZP} 1_{k j p l t} \\
& p \in P ; k \in K ; k^{\prime} \in U ; t \in T \\
& p \in P ; k \in K ; k^{\prime} \in U ; t \in T \\
& \mathrm{XF}_{p k^{\prime} t}^{\prime}+\mathrm{XF}_{p k t}=\sum_{l \in L} \sum_{j \in J} \mathrm{ZF} 1_{k j p l t} \\
& \mathrm{DF}_{p i t}=\sum_{j \in J} \sum_{l \in L} \mathrm{ZF} 2_{j i p l t-d_{l}} \\
& p \in P ; i \in I ; t \in T\left(t \geq d_{l}\right) \\
& p \in P ; i \in I ; t \in T\left(t \geq d_{l}\right) \\
& \mathrm{DP}_{\text {pit }}=\sum_{j \in J} \sum_{l \in L} \mathrm{ZP} 2_{j i p l t-d_{l}} \\
& \sum_{p \in P} V_{p} *\left(\mathrm{ZF} 1_{k j p l t}+\mathrm{ZP} 1_{k j p l t}\right) \leq \mathrm{NP} 1_{k j l t} * C_{l} \\
& k \in K ; j \in J ; l \in L ; t \in T \\
& \sum_{p \in P} V_{p} *\left(\mathrm{ZF} 2_{j i p l t}+\mathrm{ZP} 2_{j i p l t}\right) \leq \mathrm{NP} 2_{j i l t} * C_{l} \\
& j \in J ; i \in I ; l \in L ; t \in T \\
& \mathrm{YP}_{p k t} \in\{0,1\} ; \quad \mathrm{YF}_{p k t} \in\{0,1\} ; \\
& \mathrm{YF}_{p k^{\prime} t}^{\prime} \in\{0,1\} ; \quad \mathrm{YP}_{p k^{\prime} t}^{\prime} \in\{0,1\} ; \\
& p \in P ; k \in K ; t \in T \\
& p \in P ; k^{\prime} \in U ; t \in T \\
& \mathrm{ZP} 1_{\text {kjplt }} \in \mathbb{N} ; \quad \mathrm{ZF} 1_{k j p l t} \in \mathbb{N} \text {; } \\
& \mathrm{ZP} 2_{\text {jiplt }} \in \mathbb{N} ; \quad \mathrm{ZF} 2_{\text {jiplt }} \in \mathbb{N} \\
& \mathrm{XP}_{p k t} \in \mathbb{N} ; \quad \mathrm{XF}_{p k t} \in \mathbb{N} \\
& \mathrm{XF}_{p k^{\prime} t}^{\prime} \in \mathbb{N} ; \quad \mathrm{XP}_{p k^{\prime} t}^{\prime} \in \mathbb{N} \\
& \mathrm{JP}_{p j t} \in \mathbb{N} ; \quad \mathrm{JF}_{p j t} \in \mathbb{N} \\
& \mathrm{NP} 1_{k j l t} \in \mathbb{N} \\
& k \in K ; j \in J ; p \in P ; l \in L ; t \in T \\
& j \in J ; i \in I ; p \in P ; l \in L ; t \in T \\
& p \in P ; k \in K ; t \in T \\
& p \in P ; k^{\prime} \in U ; t \in T \\
& p \in P ; j \in J ; t \in T \\
& k \in K ; j \in J ; l \in L ; t \in T \\
& \mathrm{NP} 2_{\text {jilt }} \in \mathbb{N} \\
& j \in J ; i \in I ; l \in L ; t \in T \\
& \mathrm{UP}_{k t} \in \mathbb{N} \\
& k \in K ; t \in T \text {. }
\end{aligned}
$$

The objective function minimizes the total supply chain network cost composed of fixed and variable production costs, total inventory holding cost, fixed and variable transportation cost from the manufacturer to the warehouse and fixed and variable transportation cost from the warehouse to the retailer, underutilization as well as overtime cost associated to the internal production capacity. Constraints (4.1) and (4.2) calculate the inventory level of products planned to meet respectively predicted orders and firm orders in warehouse $j$ at the end of period $t$. Constraints (4.3) guarantee that the total stored quantity does not exceed storage capacity. Constraints (4.4)-(4.7) ensure the relationship between binary and integer variables while ensuring the manufacturing of 
products on already launched lines. Constraints (4.8)-(4.13) ensure that overtime production cost is considered only in the case that there is no production of the same products previously. Constraints (4.14) and (4.15) ensure the consideration of production capacity during both regular working time and overtime with respect to the production capacity of the manufacturing units. Constraints (4.16) and (4.17) ensure that during the first period of the planning horizon only confirmed orders are planned and processed. Subsequently, planned product quantities to meet demand forecast over the first period are equal to zero. Constraints (4.18)-(4.22) guarantee that monthly assignment tactical decisions are detailed over weeks at the operational level respecting all made decisions until the end of the month. Constraints (4.23) with the objective function define the underutilized internal production capacity. The distribution of all produced quantities to warehouses is enforced by constraints (4.24) and (4.25). Constraints (4.26) and (4.27) guarantee that the planned product quantities for delivery satisfy the demand of each retailer. The transportation of total quantities from manufacturing plants to warehouses and from warehouses to retailers with respect to transportation capacities is guaranteed by constraints (4.28) and (4.29).

\section{Demand estimation}

In this section, we describe the method considered to forecast demand with information sharing.

\subsection{Replenishment order forecast}

To forecast replenishment orders, we will follow the following four steps:

- The first step consists in developing the logistic diffusion forecasting model by defining its parameters: (1) the long-term saturation level, (2) the period of inflection, and (3) the intensity of the introduction phase.

- The second step involves the construction of the cumulative sales curve. This step also includes forecasting sales of the next periods using the logistic diffusion model.

- The third step consists in defining order points and the quantities to deliver to retailers. To do this, we predict retailer replenishment policy based on historical data.

- Finally, forecasts of replenishment orders are used as inputs in the operational planning model.

Once confirmed information regarding cumulative sales is received, this four-step forecasting scheme is used to update the forecasts over the weekly rolling horizon.

\subsection{Logistic diffusion model}

For the purpose of illustration, we detail the different steps of the adopted logistic diffusion model [26] for one apparel product.

We assume that the lifespan of an apparel product is about 24 weeks which is the length of the corresponding selling season. For example, the products that are placed onto retail points in March are part of summer collection and will be sold until the end of august. Hence, in order to forecast the sales of a given product, we construct its life cycle curve on the 24 weeks of its selling season. To do this, we use the logistic diffusion forecast model where cumulative sales $Y_{t}$ are defined as a function of time $t$ as indicated below in equation (5.1):

$$
Y_{t}=\frac{S}{1+B e^{-A t}}
$$

$S$ is the long run saturation level;

$A$ is a delay factor which indicates the intensity of the introductory stage of a given product life cycle; $B=e^{I * A}$ where $I$ is the inflection point. In this model, cumulative sales at the inflection point $I$ are $50 \%$ of cumulative sales at the long run, when saturation is reached.

In this study, the saturation level of each product is deduced from sales historical data of the previous year. $S$ is set to the maximum sales achieved for the products of the same family sold during the same season of the previous year. For all products, we assume that half of their total sales is reached in the middle of their selling season (at week 12 of the selling season). Hence, $I$ is set to 12 . 
Let us consider the example of product TM680 which is a classic knitting tee-shirt of the summer collection. We assume that $S$ is equal to 2200 for TM680, and verify that half of the threshold $S$ is reached in June, at the middle of its selling season.

At this level we need to determine $A$ in order to establish the cumulative sales curve. For that, we consider sales data shared by the retailer and the orders received from and/or delivered to the retailer during the weeks of the selling season.

For instance, the pre-season order quantity for TM680 is 570 units. This quantity has been delivered to the retailer during the first week of the season. Furthermore, according to the retailer, 198 units of TM680 have been sold over the first week of the selling season.

Based on this information, we can conclude that the point $(1,198)$ belongs to the logistic curve and hence verifies equation (5.1).

$$
198=\frac{2200}{1+e^{A *(12-1)}}
$$

From equation (5.2), we can then deduce that $A$ is equal to 0.21 and the cumulative sales can be forecasted using equation (5.3):

$$
Y_{t}=\frac{2200}{1+e^{0.21 *(12-t)}}
$$

After that, using (5.3), we can construct the forecasted curve of product TM680 life cycle (see Fig. 4).

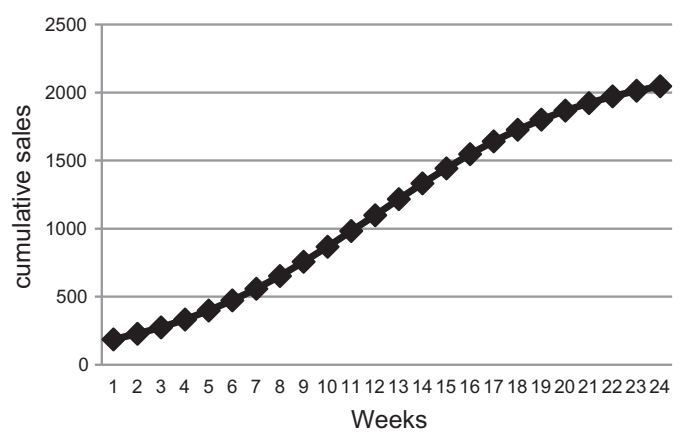

Figure 4. TM680 cumulative sales.

From product life cycle curve or directly using (5.3), we forecast the weekly sales as mentioned in Table 1.

TABLE 1. Forecast TM680 sales.

\begin{tabular}{llll}
\hline \hline Week & Sales/Week & Week & Sales/Week \\
\hline 2 & 40 & 14 & 116 \\
3 & 48 & 15 & 110 \\
4 & 56 & 16 & 103 \\
5 & 66 & 17 & 95 \\
6 & 75 & 18 & 85 \\
7 & 85 & 19 & 75 \\
8 & 95 & 20 & 66 \\
9 & 103 & 21 & 56 \\
10 & 110 & 22 & 48 \\
11 & 116 & 23 & 40 \\
12 & 118 & 24 & 34 \\
13 & 118 & & \\
\hline
\end{tabular}


Suppose that usually three replenishment orders are expected to arrive from the considered retailer over the selling season. The first order arrives in general one month after the start of the season, the second order arrives in general two months after the start of the season, while the third one arrives in general after 3 months after the start of the season. The delivery lead time is of 3 weeks.

These three replenishment orders have to be forecasted and introduced in the operational planning. Based on sales forecasts presented in Table 1, we can note that at week 7 the cumulative sales are close to 570 units and a delivery is needed to avoid stock-out. Hence we can anticipate that the first replenishment order will arrive at the end of week 4 and delivered at end of week 7. Moreover, the ordered quantity should cover the sales until week 11, as this is supposed to be the delivery date of the second replenishment order. The cumulative sales at week 11 amount to 992 units and hence the forecast of the ordered quantity is 422 units.

At the end of week 7, according to the retailer, 345 units have been sold. This sales information is henceforth used to update the logistic curve using the point $(7,345)$. Cumulative sales can be determined using equation $(5.4)$.

$$
Y_{t}=\frac{2200}{1+e^{0.34 *(12-t)}} .
$$

The product cycle life curve is updated accordingly as shown in Figure 5 below:

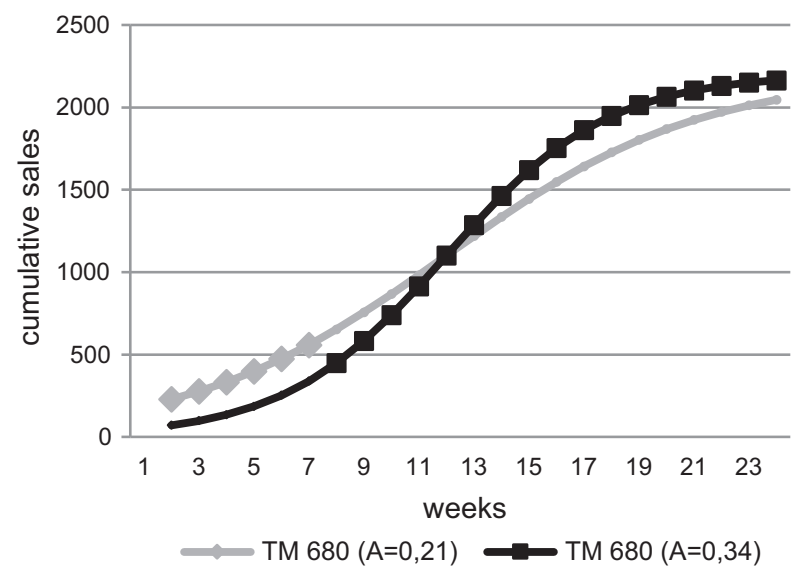

FiguRE 5. TM680 updated cumulative sales.

As the forecast for cumulative sales at week 11 is 914 units and in week 12 is 1100 units, the manufacturer anticipates the receipt of a second replenishment order in week 8 for a delivery in week 11 . The ordered quantity should cover the sales until week 15. At week 15, the forecast for cumulative sales is 1619 units. Hence the anticipated order quantity will be 649 units. The same scheme will be repeated to forecast the third replenishment order.

The first replenishment order can be accounted for while constructing the operational plan of the second week of the selling season. Any update of the forecast can be thereafter introduced over the weekly rolling horizon. When a firm replenishment order arrives, it of course replaces the forecasted one.

\section{Computational experiments}

In this section, we first present the considered case study. Then, we present the conducted experimentation and the obtained results. Finally, we present the results of the sensitivity analysis that has been carried out to investigate the effect of some parameters on supply chain performance. 


\subsection{Case study}

In this paper, our experimentation focuses on knitting products. This business, with almost 200 different references produced and delivered per year, is amongst the most important activities of the company. Production is performed in three knitting company-owned manufacturing plants with limited production capacities. Production flexibility is reinforced through subcontracting. Eleven subcontractors are involved in the company's network: Ten local and one overseas, located China. Local subcontractors offer prices generally $20 \%$ higher than the unit costs of internal production. The Chinese subcontractor, however, offers relatively lower prices (the price offered for some basic products may be half of their unit production cost in internal manufacturing units). However, in this case, subcontracting needs to be planned sufficiently in advance because it involves a 6 -week shipping lead time. Produced items are transported to two local warehouses and then to retailers using a combination of the transportation modes mentioned above for those located overseas. The inventory holding cost per unit is about $5 \%$ of its production cost. Pre-season orders are received well in advance, often six to four months before the start of the selling season, whereas for the replenishment orders, the delivery lead time is in general of three weeks. An underutilization cost corresponding to fixed expenses incurred by idle production, is supposed to be the third of the internal production cost. Overtime production costs $40 \%$ higher than production during regular hours. The considered company considers only overtime and subcontracting to handle demand variability and satisfy the demand.

In this work, we propose to simulate our tactical-operational production-distribution planning approach over six months. Since we have three-year historical data, we propose to test our approach using available two-year historical data and then compare what our method proposes for the third year with regard to what was really realised.

We begin by presenting the results of the experimentation based on information sharing between the retailer and the producer. Replenishment order forecasts obtained by the logistic diffusion model are thus taken into account in the operational planning. We compare the results of this work to those obtained in the absence of information sharing. Finally, we test our approach with perfect forecasts, where all predicted replenishment orders are confirmed and arrive actually through the rolling horizon.

All MILP models are solved using the package ILOG OPL Studio V6.3/Cplex 12, on a PC Intel Core i5 with a $2.3 \mathrm{GHz}$ processor and $512 \mathrm{MB}$ memory.

\subsection{Experimentation and results}

First, we evaluate the impact of considering information sharing on the supply chain performance. Second, we present a comparative study considering different planning approaches. The objective is to highlight the benefits and value of information sharing.

\subsubsection{Planning approach considering information sharing}

We first calculate the supply chain cost over six months in the presence of information sharing. In order to stress the importance of introducing a reserve production capacity at the tactical planning level, the supply chain cost is calculated for three types of production-distribution plans: (1) plans constructed without considering a reserve production capacity, (2) plans constructed while considering a fixed reserve production capacity of $20 \%$, and (3) plans constructed while considering a monthly variable reserve production capacity. These three scenarios will be referred to as WIRP, WFRP-20\% and WMVRP, respectively. For more details on how a monthly variable reserve production capacity is estimated and incorporated in the tactical model, we refer the reader to Safra et al. [34]. Table 2 reports the obtained costs.

The results of Table 2 point out the interest of considering a monthly-varying reserve production capacity at the tactical planning level as it allows to reduce the supply chain cost by $4 \%$. In particular, one can notice the substantial reduction in overtime production, underutilization and subcontracting costs against production costs (over regular hours) which are higher than those of the other scenarios (WIRP and WFRP-20\%). This increase highlights a better utilization of the internal production capacities. In fact, the reduction in total cost is explained on the one hand, by the reduction in overtime and subcontracting costs, which are always higher than 
TABLE 2. Supply chain costs (K€) obtained by the approach considering information sharing.

\begin{tabular}{|c|c|c|c|c|c|c|c|}
\hline & $\begin{array}{l}\text { Production } \\
\text { cost }\end{array}$ & $\begin{array}{l}\text { Overtime } \\
\text { production } \\
\text { cost }\end{array}$ & $\begin{array}{l}\text { Subcontracting } \\
\text { cost }\end{array}$ & $\begin{array}{l}\text { Transportation } \\
\text { cost }\end{array}$ & $\begin{array}{l}\text { Inventory } \\
\text { holding } \\
\text { cost }\end{array}$ & $\begin{array}{l}\text { Underutilization } \\
\text { cost }\end{array}$ & $\begin{array}{l}\text { Overall } \\
\text { cost }\end{array}$ \\
\hline WIRP & 2019 & 20 & 144 & 199 & 21 & 25 & 2429 \\
\hline WFRP-20\% & 2045 & 15 & 115 & 198 & 13 & 20 & 2411 \\
\hline WMVRP & 2057 & 1 & 56 & 196 & 16 & 3 & 2332 \\
\hline
\end{tabular}

the cost generated by the increase of production in regular hours. Indeed, the monthly-varying reserve capacity considered at the tactical level allows to accommodate orders that arrive at the operational level without having to recourse to overtime or subcontracting activities. On the other hand, the underutilization cost of the internal capacity is considerably low when a monthly-varying reserve capacity is adopted, given that the latter is well estimated according to reliable order forecasts at an operational level.

Concerning the inventory holding cost, considering a monthly-varying reserve capacity entails lower costs than those of the first scenario (WIRP); but higher costs than those of the second scenario (WFRP-20\%). Indeed, when considering a monthly-varying reserve capacity, some productions are anticipated and advanced over months when internal production capacity is available, knowing replenishment order forecasts, which generates a moderately high inventory holding cost. The transportation cost remains stable for the three considered scenarios since almost the same quantities are delivered given the ordered quantities. Cost savings are achieved mainly due to the improvement of internal production capacity utilization, while considering an adequate reserve production capacity at the tactical planning level.

Figure 6 portrays production assignment for the three considered scenarios and hence comes to support the previous analysis. As it can be noticed, the best production assignment is obtained for the third scenario (WMVRP) where $94.7 \%$ of the total demand is produced internally over regular hours, while the rest is produced using overtime $(0.1 \%)$ or subcontracting $(5.2 \%)$. These results confirm, once again, that a better use of internal resources can be achieved if the manufacturer opts for introducing a monthly-varying reserve capacity at the tactical planning.

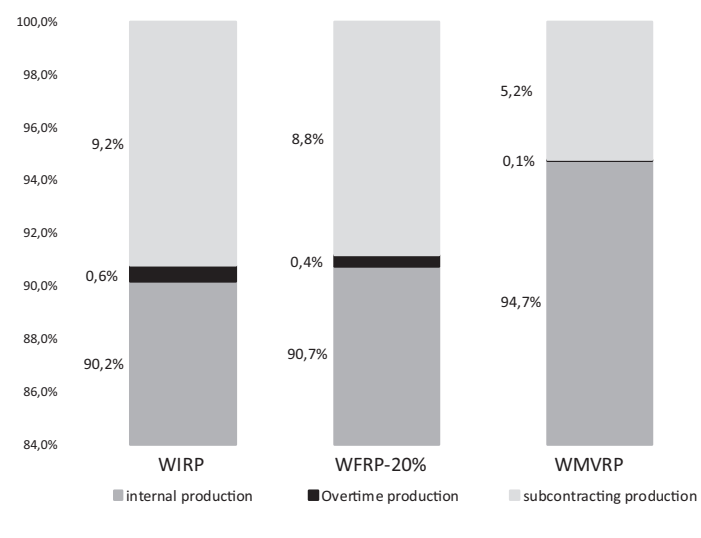

Figure 6. Production assignment. 


\subsubsection{Comparison of planning approaches}

In order to shed the light on the benefits and the value of information sharing, first we compare the results obtained by the planning approach considering information sharing (hereafter referred to as A2) to the ones obtained by a planning approach without information sharing (hereafter referred to as A1). The latter are extracted from Safra et al. [34] which explores a planning approach without information sharing using the same case study.

Table 3 compares production assignments obtained by A1 and A2 for the three scenarios WIRP, WFRP-20\% and WMVRP.

TABLE 3. Comparison of production assignments.

\begin{tabular}{lllllll}
\hline \hline & \multicolumn{2}{c}{ WIRP } & \multicolumn{2}{c}{ WFRP-20\% } & \multicolumn{2}{c}{ WMVRP } \\
\cline { 2 - 7 } & A1 & A2 & A1 & A2 & A1 & A2 \\
\hline Regular hour production & 259359 & 259832 & 259654 & 261641 & 259727 & 268690 \\
Overtime production & 1833 & 1746 & 1401 & 1281 & 2303 & 154 \\
Subcontracted production & 25507 & 26590 & 35373 & 25482 & 16793 & 14785 \\
Total quantities & 286699 & 288168 & 296428 & 288404 & 278823 & 283629 \\
\hline
\end{tabular}

Notes. A1: Approach without information sharing. A2: Approach considering information sharing.

We notice that when retailer shares sales information with producer, a better use of the internal production capacity is accomplished whether considering or not a reserve production capacity at the tactical level. This sharing of information enables the company to anticipate the arrival of replenishment orders and hence to produce the ordered quantities internally at a lower cost. However, the best internal production capacity utilization is observed when a monthly-varying reserve production capacity is used at the tactical level given that this reserve, which is better estimated with reliable forecasts, allows to adjust internal capacity to accommodate orders. It is also worth noting that the increase in produced quantities at internal production sites is accompanied by a decrease in overtime and a decrease in subcontracted quantities except for the case where the full production capacity is used at the tactical level since no flexibility is provided to accommodate orders at the operational level. In this case, subcontractors' production has increased in A2 with comparison to A1. This increase is explained by advanced production of some quantities using internal capacities or subcontractoring. Such a planning decision is made due to: (1) the high cost of overtime production in comparison to competitive prices offered by subcontractors, (2) the use of full internal production capacity available at the tactical planning level and (3) the unavailability of internal capacity when planning newly arrived orders at the operational level.

As it can be noted, the total quantities manufactured over the 6 months are not similar for the three scenarios (WIRP, WFRP-20\% and WMVRP) given that some orders placed over the six months have to be delivered to customers at a due date beyond the six month planning period. These orders can be processed in advance when the available production capacity is able to accommodate them and then transported by ships to customers. Otherwise, the related production will be delayed for the next months, beyond the six month planning period, as the due date is not yet reached. In the second scenario (WFRP-20\%), the reserve production capacity at the tactical level allows the production of advanced quantities with lower costs, when internal capacities are available at the operational planning level. This leads to higher produced quantities over the six months comparing to the other two scenarios (WIRP and WMVRP). Nevertheless, when a monthly-varying reserve production capacity is considered, these advanced productions are lower since the adjusted available capacity accommodates only the necessary quantities.

Furthermore, our approach is tested while assuming perfect forecasts. In this case all replenishment order forecasts are confirmed by firm orders received from the retailer, i.e., we assume that the forecast error is equal 
to zero. A planning approach with information sharing and in which we assume perfect forecasts is hereafter referred to as A3.

Table 4 provides supply chain costs obtained by A1, A2 and A3 for the three scenarios WIRP, WFRP-20\% and WMVRP. Expectedly, the highest cost is the one tied to A1 without consideration of a reserve production capacity at the tactical planning. This reflects the current practice in the considered company. Moreover, Table 4 gives the cost saving that can be achieved for each approach over the current practice.

TABLE 4. Cost comparison.

\begin{tabular}{lllllll}
\hline \hline & \multicolumn{2}{c}{ WIRP } & \multicolumn{2}{c}{ WFRP-20\% } & \multicolumn{2}{c}{ WMVRP } \\
\cline { 2 - 7 } & $C$ & CS & $C$ & CS & $C$ & CS \\
\hline A1 & 2864 & $0 \%$ & 2746 & $4 \%$ & 2575 & $10 \%$ \\
A2 & 2429 & $15 \%$ & 2411 & $16 \%$ & 2332 & $18 \%$ \\
A3 & 2396 & $16 \%$ & 2364 & $17 \%$ & 2285 & $20 \%$ \\
\hline
\end{tabular}

Notes. A1: Approach without information sharing. A2: Approach considering sharing information. A3: Approach considering information sharing tested while assuming perfect forecasts. C: Total cost (K€). CS: Cost saving (\%).

The results in Table 4 demonstrate that the adoption of a planning approach with information sharing and a monthly-varying reserve production capacity allows the company to achieve a cost saving of $18 \%$ over the current practice. The cost saving can reach $20 \%$ in the case of perfect forecasts. This obviously highlights the interest to develop a reliable and efficient forecast system. Indeed, such a system will accurately estimate the monthly-varying reserve production capacity and predict the replenishment orders. The latter can be therefore integrated in the operational planning at a lower cost.

\subsection{Sensitivity analysis}

A sensitivity analysis is carried out in order to study the impact of some parameters on planning decisions and the performance of the considered supply chain. Three parameters are considered in this analysis: demand, transportation cost and subcontracting cost. Indeed, these parameters may be subject to fluctuations because of different factors such as competition, economic conditions, or disruptions due to natural disasters such as the COVID-19 pandemic.

In our experimentation, we constructed production-distribution plans while varying the value of the (1) demand, (2) transportation cost and (3) subcontracting cost from -50 to $+50 \%$, around their current values. Moreover, we compared the supply chain cost obtained by a planning approach considering information sharing and a monthly-varying reserve production capacity (A2-WMVRP) to the supply chain cost obtained by the current practice (A1-WIRP).

\subsubsection{Sensitivity analysis of demand}

The results reported in Table 5 clearly show the superiority of A2-WMVRP over A1-WIRP, which reflects the current practice in facing demand variation. Indeed, even when the demand is reduced by half, the cost remains lower for A2-WMVRP. However, as it can be noticed, the gap between costs gets smaller when demand decreases. This is due to the fact that internal production sites can satisfy lower demand without considering a reserve production capacity at the tactical level and without sharing information. However, the adoption of a planning approach with information sharing and a monthly-varying reserve production capacity has a significant effect on supply chain cost reduction in the case of a surge in the demand. The adoption of this approach yields a $19 \%$ reduction in the supply chain cost when the demand increases by $20 \%$ and $50 \%$. 
TABLE 5. Effect of demand variation on supply chain cost.

\begin{tabular}{llllll}
\hline \hline & $D-50 \%$ & $D-20 \%$ & $D$ & $D+20 \%$ & $D+50 \%$ \\
\hline A1-WIRP (K€) & 1658 & 2152 & 2864 & 3285 & 3794 \\
A2-WMVRP (K€) & 1601 & 1898 & 2332 & 2653 & 3055 \\
Gap (\%) & 3 & 12 & 18.6 & 19 & 19 \\
\hline
\end{tabular}

\subsubsection{Sensitivity analysis of transportation cost}

Once again, as shown in Table 6, a planning approach with information sharing and considering a monthlyvarying reserve production capacity (A2-WMVRP) outperforms the one currently used by the considered company (A1-WIRP) when overseas transportation cost fluctuates.

TABLE 6. Effect of overseas transportation cost variation on supply chain cost.

\begin{tabular}{llllll}
\hline \hline & $T-50 \%$ & $T-20 \%$ & $T$ & $T+20 \%$ & $T+50 \%$ \\
\hline A1-WIRP $(\mathrm{K} €)$ & 2424 & 2678 & 2864 & 2891 & 2894 \\
A2-WMVRP (K€) & 2260 & 2301 & 2332 & 2356 & 2358 \\
Gap (\%) & 6 & 14.1 & 18.6 & 18.5 & 18.5 \\
\hline
\end{tabular}

On the one hand, when the overseas transportation cost decreases, the supply chain cost also decreases. More importantly, we notice a migration of some productions from internal production sites to the manufacturing units of overseas subcontractors (Fig. 7). Expectedly, a reduction in overseas transport costs favors the recourse to overseas subcontracting as the latter offers lower unit production costs compared to those of local production mainly for basic products.

On the other hand, we note a small increase of the supply chain cost when the overseas transportation cost increases. In this case, overseas subcontracting becomes an expensive option. As shown in Figure 7, an increase of overseas transportation cost fosters production in local manufacturing units. Moreover, this explains the observed cost stability in supply chain cost despite the significant increase of overseas transportation cost (50\%). In this case, A2-WMVRP allows a better deployment of internal production capacity and local subcontracting that results in $18.5 \%$ reduction of the supply chain cost with comparison to A1-WIRP.

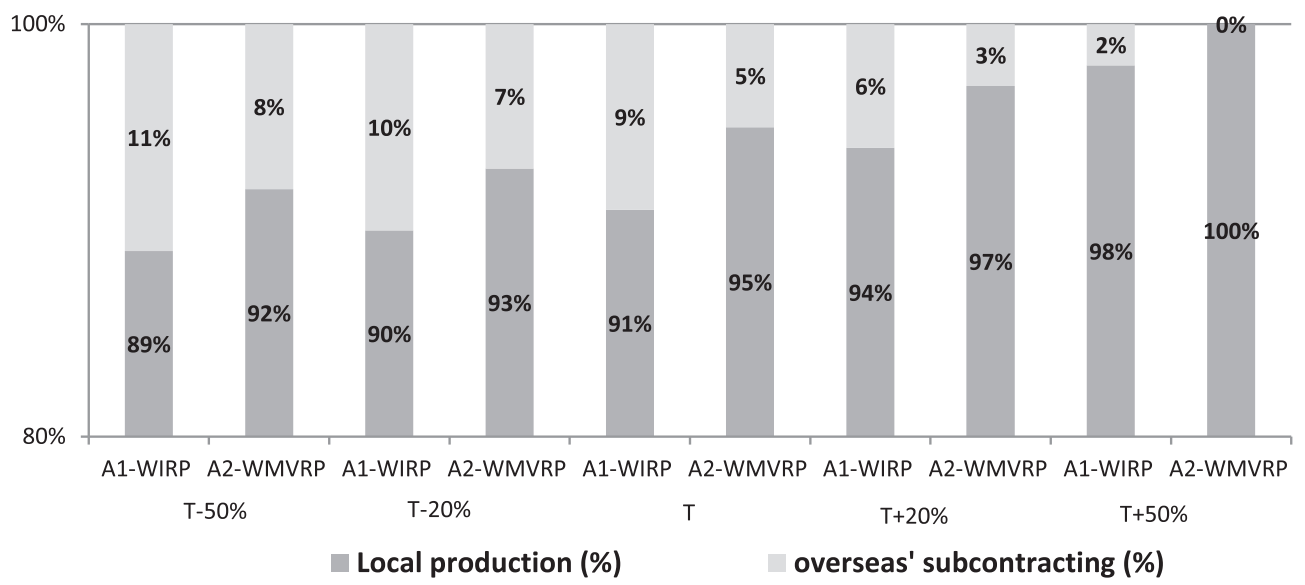

FigURE 7. A comparison of production assignment for the two approaches. 


\subsubsection{Sensitivity analysis of subcontracting cost}

Table 7 reports the effect of local subcontracting cost variation on supply chain cost. When the cost of local subcontracting is reduced by half, it becomes more cost competitive than internal production. So a large part of the internal production is assigned to local subcontractors. Indeed, underutilization cost of internal production capacity impedes the subcontracting of the total quantities. This obviously leads to a lower supply chain cost explained by a decrease in production costs. As shown in Table 7, the gap between the two approaches gets smaller when local subcontracting cost decreases. Hence the value of information sharing is lessened in this case as local subcontracting becomes a lever to efficiently face demand variation. Oppositely, the increase of local subcontracting cost can only encourage the producer to plan its capacity as well as possible in order to meet urgent demand that may occur at the operational level without using costly subcontracting, and this is ensured through information sharing with the retailer. The value of information sharing is highlighted by the significant gap estimated at $19 \%$ between the supply chain cost of A2-WMVRP and A1-WIRP.

TABLE 7. Effect of subcontracting cost variation on supply chain cost.

\begin{tabular}{llllll}
\hline \hline & $S-50 \%$ & $S-20 \%$ & $S$ & $S+20 \%$ & $S+50 \%$ \\
\hline A1-WIRP (K€) & 2509 & 2798 & 2864 & 2925 & 2964 \\
A2-WMVRP (K€) & 2305 & 2321 & 2332 & 2382 & 2408 \\
Gap (\%) & $8 \%$ & $17 \%$ & $18.6 \%$ & $18.6 \%$ & $19 \%$ \\
\hline
\end{tabular}

\subsection{Managerial insights}

The proposed multi-level integrated production-distribution planning approach with information sharing and considering a monthly-varying reserve production capacity is particularly recommended for supply chains that provide products having the same features of textile and apparel items i.e. having a volatile demand lacking historical data, and where manufacturers need to process simultaneously orders with long delivery times and orders with relatively short lead times. In this case, sharing of sales data allows the producer to predict the orders with relatively short lead time and hence integrate them when received in a more cost-effective way. On the other hand, the retailer can benefit from this information sharing as its urgent demand can be timely satisfied. Information sharing results in a significant decrease of supply chain cost.

In the current context, it is not enough for the manufacturer to focus on developing desirable products; he must also provide products at the right time and at reasonable prices. Adopting an integrated planning approach with information sharing between supply chain actors, that emphasizes flexibility and responsiveness is the key to achieving cost reduction and a competitive edge. Supply chain performance can be further improved if more sophisticated methods for estimating monthly reserve production capacity and forecasting replenishment orders are developed. Besides, a reinforced retailer-manufacturer partnership involving more exhaustive information sharing and collaborative forecasting would also improve the performance of the supply chain.

The interest of adopting a planning approach with information sharing and a monthly-varying reserve production capacity significantly increases when demand, overseas transportation cost and subcontracting cost increase. But even if there is a decrease in the value of these parameters, the planning approach with information sharing and a monthly-varying reserve production capacity remains superior to the current practice. Therefore, a planning approach with information sharing outperforms the current practice in case a disruption such as the COVID-19 pandemic occurs.

As a result of COVID-19 crisis, companies in the textile and apparel sector are caught in a double bump. On the one hand, a supply shock arises in the sequel of the slowdown in international trade and local supply linked to the confinement within the country. This supply chock was accompanied by a demand shock with a drop in activity caused by the absence or fear of consumers. In our case where part of the production is subcontracted 
overseas and most of the sales are exported, these two shocks may be external or internal in origin. The external shocks come firstly from the decline in demand for exports of textile and apparel products. They also stem from difficulties in supplying local producers with imports. The internal shocks come from the decline in activity in the country following the confinement and reduction of demand in the non-food sectors in general and in the textile and apparel sector in particular. Three main changes are hence entailed by the above-mentioned schocks. Firstly, demand is negatively impacted by the sector's lower exports and lower consumption and the periodic closures of stores. Secondly, overseas transport costs increase due to the control and waiting phenomena at border areas. To avoid longer shipping lead times and higher overseas transportation costs, companies are hence favoring local subcontractors. Hence local subcontacting cost is expected to increase in the near future. Our results reveal that the planning approach with information sharing is more cost effective than the one without information sharing in the sequel of these changes. Moreover, our approach can be used to evaluate in a more precise way the effect of the company's new operating conditions in the context of the COVID-19 crisis on the performance of the textile supply chain under consideration.

\section{ConClusion AND FURTher RESEARCH}

This study aims to provide the textile and apparel supply chain managers with a decision support tool that allows them to achieve a better match between supply and demand while considering: (1) production and distribution activity coordination, (2) temporal coordination through the integration of tactical and operational decisions, and (3) reliable replenishment order forecasts enabled by information sharing on current in-season sales. Linear programming models are used to optimize production and distribution plans by considering capacity and material balance constraints. A two-stage approach is proposed for the multi-site supply chain, multi-product and multi-period planning models at the tactical and operational decision levels. Tactical decisions, allowing an adjusted reserve production capacity, are detailed at the operational model considering a variable rolling horizon. The information sharing provides the producer with better visibility on the future replenishment orders and contributes to better matching the supply to the demand.

This work relies on information sharing to better match supply and demand in the textile and apparel supply chain. In fact, information sharing along the supply chain reduces costs by $15 \%$. However, when information sharing is coupled with reserve production capacity at the tactical level, the cost cutting attains $18 \%$. Moreover, perfect forecasts yield a cost saving of $20 \%$, amounting to $573 \mathrm{M} €$ per six months. This can be achieved when retailer-manufacturer partnership is reinforced and shared information is exhaustive; that is, when retailers communicate their sales data and their inventory management policy with the manufacturer.

This work developed an approach that helps textile and apparel manufacturer decision maker place production orders while accounting for demand uncertainty and striving for cost cutting and customer satisfaction. The cost reduction provided by the proposed sequential approach, which takes into account information sharing, enables the company to maintain its market share and remain competitive even in difficult situations and in crisis time. On the other hand, thanks to gains generated and when demand recovers after a potential crisis, the manager would be encouraged to extend production, invade other markets, establish other contracts and make an optimal choice of its partners (suppliers and subcontractors) in order to make higher profits. That is to say that the proposed approach helps the manager to react quickly to market conditions by reconfiguring optimally his production resources, if necessary, and making a better choice of partners' locations.

The developed approach emphasizes the importance of information sharing among supply chain actors so that the performance rises, especially for specific industrial fields characterized by their global supply chain and operating in a volatile market featured by variable demand arriving at different horizons and short-life-cycle products. It can be applied to other sectors where the demand is unstable and changing and where orders emanate at a tactical and operational levels. It's particularly the case of industries with two kinds of customers: premium customers with unpredictable requirements on a tactical level but who pay more, and classic or regular customers with longer and predictable orders. Different scenarios can also be tested, possibly acting on variables other than those proposed for the performance study such as lead times, production or transportation capacity, 
availability of manufacturing units. Thus, the use of our models should make it possible not only to reduce costs and improve industrial reactivity, but also to deduce other results for the improvement of the company's overall performance by anticipating the effect of variations in some parameters (such as demand, production, transport or storage capacities...) by establishing action plans that will be useful following unpredictable events such as the COVID-19 crisis. Moreover, our models, applied to larger sized problems, can lead to additional complexity and need the development of more sophisticated methods such as relaxation or decomposition based methods or meta-heuristics to obtain near-optimal solutions. Another important perspective of this research lies in the consideration of uncertainties tied to the demand and the supply in the integrated production and distribution planning of the textile and apparel supply chain. Henceforth, the development of a stochastic approach for this decision problem constitutes one of the prominent extensions of the current work.

\section{Appendix A. Tactical planning model}

In model formulation, we consider the following sets and indices, parameters, and decision variables.

\section{Sets and indices}

$K$ : set of manufacturing units $k \in K ; K=U \cup V$.

$U$ : set of internal manufacturing units, $k \in U$.

$V$ : set of subcontractors' manufacturing units, $k \in V$.

$I$ : set of retailers, $i \in I$.

$J$ : set of warehouses, $j \in J$.

$P$ : set of products, $p \in P$.

$L$ : set of transportation modes, $L=\{$ trucks, ships, aircraft $\}, l \in L$.

$T$ : set of periods included in the planning horizon, $t \in[1, \ldots,|T|]$.

\section{Parameters}

In this tactical model, each retailer $i$ expresses a demand for product $p$ to be delivered at period $t\left(D_{\text {pit }}\right)$. Orders are assigned to manufacturing units characterized by a monthly limited production capacity $\left(U_{k t}\right)$ where production takes place, incurring variable and fixed monthly production costs $\left(C_{p k t}, S_{p k t}\right)$ or monthly subcontracting costs $\left(G_{p k t}\right)$. A monthly underutilization cost of internal production capacity $\left(\mathrm{CSU}_{k t}\right)$ is also considered to penalize the unused available resources. Each product is characterized by a production lead time $\left(T p_{p}\right)$ and a products' unit volume $\left(V_{p}\right)$. Manufactured quantities are then transported to warehouses where monthly inventory holding costs $\left(\mathrm{KP}_{p j t}\right)$ are incurred. Warehouses' storage capacity $\left(W_{j}\right)$ is limited. Transportation modes are characterized by a limited monthly transportation capacity $\left(C_{a p}\right)$ and a transportation lead time $\left(e_{l}\right)$. Variable and fixed distribution costs from manufacturing units to warehouses $\left(\mathrm{CT}_{k j p l t}, \mathrm{CF}_{k j p l t}\right)$ and from warehouses to retailers $\left(\mathrm{CS}_{j i p l t}, \mathrm{CFS}_{j i p l t}\right)$ are also considered. We denote the percentage of internal production capacity that can be used to fulfil pre-season orders by $\alpha_{k t}(k \in U)$. As it can be noted, $\left(100-\alpha_{k t}\right)$ represents the percentage of internal capacity reserved to fulfil in-season replenishment orders. Obviously, for $k \in V$ ( $V$ is the set of subcontractors' manufacturing units), $\alpha_{k t}=0$.

\section{Decision variables}

$Z 1_{\text {kjplt }}$ : transported quantity of product $p$ from manufacturing unit $k$ to warehouse $j$ over period $t$ via transportation mode 1 .

$Z 2_{\text {jiplt }}$ : transported quantity of product $p$ from warehouse $j$ to retailer $i$ over period $t$ via transportation mode $l$.

$X_{p k t}$ : quantity of product $p$ produced in manufacturing unit $k$ over period $t$.

$\mathrm{SU}_{k t}$ : unused production capacity at internal manufacturing unit $k$ over period $t$.

$J_{p j t}$ : inventory level of product $p$ in warehouse $j$ at the end of period $t$.

$Y_{p k t}=1$ : if product $p$ is produced in manufacturing unit $k$ over period $t ; 0$ otherwise. 
$N 1_{k j l t}$ : transported quantity from manufacturing unit $k$ to warehouse $j$ over period $t$ by use of transportation mode $l$.

$N 2_{j i l t}$ : transported quantity from warehouse $j$ to retailer $i$ over period $t$ by use of transportation mode $l$.

Model formulation (M1)

The tactical production-distribution planning model is formulated as an ILP that aims at minimizing the overall cost in the considered supply chain network.

$$
\begin{aligned}
\operatorname{Min} & \left(\sum_{t \in T} \sum_{p \in P} \sum_{k \in V} C_{p k t} X_{p k t}+\sum_{t \in T} \sum_{p \in P} \sum_{k \in V} S_{p k t} Y_{p k t}+\sum_{t \in T} \sum_{p \in p} \sum_{k \in v} G_{p k t} X_{p k t}+\sum_{k \in V} \sum_{t \in T} \mathrm{CSU}_{p k t} \mathrm{SU}_{p k t}\right. \\
& \times \sum_{j \in J} \sum_{t \in T} \sum_{p \in P} \mathrm{KP}_{p j t}\left(J_{p j t-1}+J_{p j t}\right) / 2+J_{p j t-1}+\sum_{t \in T} \sum_{p \in P} \sum_{k \in K} \sum_{l \in L} \sum_{j \in J} \mathrm{CT}_{k j p l t} * V_{p} * Z 1_{k j l p t} \\
& +\sum_{t \in T} \sum_{p \in P} \sum_{i \in I} \sum_{l \in L} \sum_{j \in J} \mathrm{CS}_{j i p l t} * V_{p} * Z 2_{j i p t}+\sum_{t \in T} \sum_{p \in P} \sum_{i \in I} \sum_{l \in L} \sum_{j \in J} \mathrm{CF}_{k j p l t} * N 1_{k j l t} \\
& \left.+\sum_{t \in T} \sum_{p \in P} \sum_{k \in K} \sum_{l \in L} \sum_{j \in J} \mathrm{CFS}_{j i p l t} * N 2_{j i l t}\right)
\end{aligned}
$$

Subject to

$$
\begin{array}{ll}
I_{p j t}=I_{p j t-1}+\sum_{l \in \mathcal{L}} \sum_{k \in \mathcal{K}} Z 1_{k j p l t-e_{l}}-\sum_{l \in \mathcal{L}} \sum_{i \in I} Z 2_{j i p l t} & j \in J ; p \in P ; t \in T ; t \geq e_{l} \\
\sum_{p \in P} I_{p j t} \leq W_{j} & j \in J ; t \in T \\
\sum_{p \in P} T p_{p} * X_{p k t} \leq \alpha_{k t} * U_{k t} & k \in K ; t \in T \\
X_{p k t} \leq M * \mathrm{Y}_{p k t} & k \in K ; p \in P ; t \in T \\
Y_{p k t} \leq X_{p k t} & k \in K ; p \in P ; t \in T \\
\mathrm{SU}_{k t} \leq \alpha_{k t} * U_{k t}-\sum_{p \in P} T p_{p} * X_{p k t} & k \in U ; t \in T \\
X_{p k t}=\sum_{j \in J} \sum_{l \in L} Z 1_{k j p l t} & k \in K ; p \in P ; t \in T \\
D_{p k t}=\sum_{j \in J} \sum_{l \in L} Z 2_{i j p l t-e_{l}} & i \in I ; p \in P ; t \in T \\
\sum_{p} V_{p} * Z 2_{j i p l t} \leq N 2_{j i l t} * C a p_{l} & j \in J ; i \in I ; l \in L ; t \in T \\
\sum_{p} V_{p} * Z 1_{k j p l t} \leq N 1_{k j l t} * C a p_{l} & j \in J ; k \in K ; i \in I ; t \in T \\
Y_{p k t} \in\{0,1\} & k \in K ; p \in P ; t \in T \\
Z 1_{k j p l t} \in \mathbb{N} ; Z 2_{j i p l t} \in \mathbb{N} ; X_{p k t} \in \mathbb{N} ; J_{p j t} \in \mathbb{N} ; N 1_{k j p l t} \in \mathbb{N} ; N 2_{j p l t} \in \mathbb{N} ; & \\
\mathrm{SU}_{k t} \in \mathbb{N} ; k \in K ; j \in J ; p \in P ; t \in T ; l \in L ; i \in I . &
\end{array}
$$

The objective function minimizes the tactical planning cost composed of variable production cost, set-up cost, subcontracting cost, internal capacity underutilization cost, inventory holding cost, variable transportation cost from manufacturing units to warehouses, variable transportation cost from warehouses to retailers, 
fixed transportation cost from manufacturing units to warehouses, and finally, fixed transportation cost from warehouses to retailers. The transportation cost is composed of a variable cost, depending on the transported quantity using a transportation mode, and a fixed cost depending on the selected transportation mode; the latter is proportional to the number of trucks, aircraft, or ships used.

Constraints (A.1) calculate the inventory level of product $p$ in warehouse $j$ at the end of period $t$. Constraints (A.2) guarantee that over each period, the total stored quantity does not exceed the warehousing capacity. Constraints (A.3) state that the produced quantities consider available internal production capacities while recognising production lead times and reserve production capacity. Constraints (A.4) and (A.5) ensure the relationship between binary and integer variables. Constraints (A.6) with the objective function define the underutilized internal production capacity. Constraints (A.7) guarantee that all produced quantities are transported to warehouses. Constraints (A.8) state that products transported from warehouses to retailers satisfy the demand with respect to delivery lead times. Constraints (A.9) and (A.10) guarantee that over each period, the transported quantities do not exceed transportation capacities. Constraints (A.11) and (A.12) are the integrality constraints.

Acknowledgements. The authors are grateful to anonymous referees for their insightful comments that helped to improve the paper.

\section{REFERENCES}

[1] A. Adhikari, A. Bisi and B. Avittathur, Coordination mechanism, risk sharing, and risk aversion in a five-level textile supply chain under demand and supply uncertainty. Eur. J. Oper. Res. 282 (2020) 93-107.

[2] A. Ait-Alla, M. Teucke, M. Lütjen, S. Beheshti-Kashi and H.R. Karimi, Robust production planning in fashion apparel industry under demand uncertainty via conditional value at risk. Math. Prob. Eng. (2014) 1-10.

[3] V.A. Armentano, A.L. Shiguemoto and A. Løkketangen, Tabu search with path relinking for an integrated productiondistribution problem. Comput. Oper. Res. 38 (2011) 1199-1209.

[4] K.F. Au, T.M. Choi and Y. Yu, Fashion retail forecasting by evolutionary neural networks. Int. J. Prod. Econ. 114 (2008) 615-630.

[5] S. Berbain, R. Bourbonnais and P. Vallin, Spécificités et problématiques des produits à durée de vie courte. In: Proceeding of the 8th International conference on Logistics and SCM Research. RIRL 2010, Bordeaux (2010).

[6] M. Boudia and C. Prins, A memetic algorithm with dynamic population management for an integrated production-distribution problem. Eur. J. Oper. Res. 195 (2009) 703-715.

[7] Z.L. Chen, Integrated production and outbound distribution scheduling: review and extensions. Oper. Res. 58 (2010) 130-148.

[8] Z.L. Chen and G.L. Vairaktarakis, Integrated scheduling of production and distribution operations. Manage. Sci. 51 (2005) 614-628.

[9] C. Ching-Chin, A.I.K. Ieng, W. Ling-Lang and K. Ling-Chieh, Designing a decision-support system for new product sales forecasting. Expert Syst. App. 37 (2010) 1654-1665.

[10] S. Chopra and P. Meindl, Supply Chain Management: Strategy, Planning and Operation, 6th edition. Pearson Education (2016).

[11] F. Darvishi, R.G. Yaghin and A. Sadeghi, Integrated fabric procurement and multi-site apparel production planning with cross-docking: a hybrid fuzzy-robust stochastic programming approach. Appl. Soft Comput. 92 (2020) 106-267.

[12] B. Fahimnia, R.Z. Farahani, R. Marian and L. Luong, A review and critique on integrated production-distribution planning models and techniques. J. Manuf. Syst. 32 (2013) 1-19.

[13] P. Farahani, M. Grunow and H.O. Günther, Integrated production and distribution planning for perishable food products. Flexible Serv. Manuf. J. 24 (2012) 28-51.

[14] H. Felfel, O. Ayadi and F. Masmoudi, Multi-stage stochastic supply chain planning in textile and apparel industry under demand uncertainty with risk considerations. Int. J. Serv. Oper. Manage. 29 (2018) 289-311.

[15] A. Ghasemi Bijaghini and S.M. SeyedHosseini, A new Bi-level production-routing-inventory model for a medicine supply chain under uncertainty. Int. J. Data Network Sci. 2 (2018) 15-26.

[16] D. Ghosh and S. Mondal, An integrated production-distribution planning of dairy industry - a case study. Int. J. Logistics Syst. Manage. 30 (2018) 225-245.

[17] A.P. Kanyalkar and G.K. Adil, An integrated aggregate and detailed planning in a multi-site production environment using linear programming. Int. J. Prod. Res. 43 (2005) 4431-4454.

[18] B.B. Keskin and H. Üster, Meta-heuristic approaches with memory and evolution for a multi-product production/distribution system design problem. Eur. J. Oper. Res. 182 (2007) 663-6820.

[19] Y. Kim, C. Yun, S. Bin Park, S. Park and L.T. Fan, An integrated model of supply Network and production planning for multiple fuel products of multi-site refineries. Comput. Chem. Eng. 32 (2008) 2529-2535. 
[20] A.A. Kurawarwala and H. Matsuo, Forecasting and Inventory Management of Short Life-Cycle Products. Oper. Res. 44 (1996) 131-150. Special Issue on New Directions in Operations Management.

[21] H. Li, G. Pedrielli, L.H. Lee and E.P. Chew, Enhancement of supply chain resilience through inter-echelon information sharing. Flexible Serv. Manuf. J. 29 (2017) 260-285.

[22] Y. Li, F. Chu, C. Feng, C. Chu and M. Zhou, Integrated production inventory routing planning for intelligent food logistics systems. IEEE Trans. Intell. Trans. Syst. 20 (2019) 867-878.

[23] S. Liu and L.G. Papageorgiou, Multiobjective optimisation of production, distribution and capacity planning of global supply chains in the process industry. Omega 41 (2013) 369-382.

[24] S.H. Liao, C.L. Hsieh and W.C. Ho, Multi-objective evolutionary approach for supply chain network design problem within online customer consideration. RAIRO:OR 51 (2017) 135-155.

[25] S. Moons, K. Ramaekers and A. Caris, Integrated production-distribution models: a state of the art. In: 29th Conference of the Belgian operational Research Society (2015).

[26] J. Morrison, How to use diffusion models in new product forecasting. J. Bus. Forecasting Methods Syst. 15 (1996) 6-9.

[27] J. Mostard, R. Teunter and R. De Koster, Forecasting demand for single-period products: a case study in the apparel industry. Eur. J. Oper. Res. 211 (2011) 139-147.

[28] J. Mula, D. Peidro, M. Díaz-Madroñero and E. Vicens, Mathematical programming models for supply chain production and transport planning. Eur. J. Oper. Res. 204 (2010) 377-390.

[29] M.E. Nenni, L. Giustiniano and L. Pirolo, Demand forecasting in the fashion industry: a review. To appear in: Int. J. Eng. Bus. Manage. (2013). DOI: 10.5772/56840.

[30] G. Pundoor and Z.L. Chen, Joint cyclic production and delivery scheduling in a two-stage supply chain. Int. J. Prod. Econ. 119 (2009) 55-74.

[31] K. Ratna Kumar, T. Radha Ramanan and S.R. Anand Abraham, Integrated production distribution problem in a partial backorder and order refusal environment. Int. J. Manage. Concepts Phil. 12 (2019) 296-311.

[32] F. Rømo, A. Tomasgard, L. Hellemo, M. Fodstad, B.H. Eidesen and B. Pedersen, Optimizing the Norwegian Natural gas production and transport. Interfaces 39 (2009) 46-56.

[33] R. Russell, W.-C. Chiang and D. Zepeda, Integrating multi-product production and distribution in newspaper logistics. Comput. Oper. Res. 35 (2008) 1576-1588.

[34] I. Safra, A. Jebali, Z. Jemai, H. Bouchriha and A. Ghaffari, Capacity planning in Textile and apparel supply chains. IMA J. Manage. Math. 30 (2019) 209-233.

[35] S. Sarkar and B.C. Giri, A vendor-buyer integrated inventory system with variable lead time and uncertain market demand. Oper. Res. 20 (2020) 491-515.

[36] S. Sarkar, B.C. Giri and A.K. Sarkar, A vendor-buyer inventory model with lot-size and production rate dependent lead time under time value of money. RAIRO:OR 54 (2020) 961-979.

[37] H. Selim, C. Araz and I. Ozkarahan, Collaborative production-distribution planning in supply chain: a fuzzy goal programming approach. Transp. Res. Part E-Logistics Transp. Rev. 44 (2008) 396-419.

[38] A. Şen and A.X. Zhang, Style goods pricing with demand learning. Eur. J. Oper. Res. 196 (2009) $1058-1075$.

[39] R. Sousa, N. Shah and L.G. Papageorgiou, Supply chain design and multilevel planning-An industrial case. Comput. Chem. Eng. 32 (2008) 2643-2663.

[40] M.W. Suh, E.K. Lee and M.T. Holt, Estimation of consumer demands: an application to US apparel expenditures. J. Textile Apparel 1 (2000) 1-9.

[41] S. Thomassey, M. Happiette and J.M. Castelain, An automatic textile sales forecast using fuzzy treatment of explanatory variables. J. Textile Apparel Technol. Manage. 2 (2002) 1-12.

[42] S. Thomassey, M. Happiette and J.M. Castelain, A global forecasting support system adapted to textile distribution. Int. J. Prod. Econ. 96 (2005) 81-95.

[43] P. Tsiakis and L.G. Papageorgiou, Optimal production allocation and distribution supply chain networks. Int. J. Prod. Econ. 111 (2007) 468-483.

[44] X. Wen, T.-M. Choi and S.-H. Chung, Fashion retail supply chain management: a review of operational models. Int. J. Prod. Econ. 207 (2019) 34-55.

[45] J. Wu, X. Zhai, C. Zhang and X. Liu, Sharing quality information in a dual-supplier network: a game theoretic perspective. Int. J. Prod. Res. 49 (2010) 199-214.

[46] T. Yang and W. Fan, Information management strategies and supply chain performance under demand disruptions. Int. J. Prod. Res. 54 (2016) 8-27.

[47] Y. Yu, Sales forecasting using extreme learning machine with applications in fashion retailing. Decis. Support Syst. 46 (2008) 411-419.

[48] Y. Yu, T. Choi and C. Hui, An intelligent fast sales forecasting model for fashion products. Expert Syst. App. 38 (2011) 7373-7379. 